\title{
MULTI-CRITERIA ANALYSIS OF ALTERNATIVE POWER GENERATION IN PARAGUAY
}

\begin{abstract}
Paraguay is a landlocked country in South America, with a surface of 406,752 km2, bordered by Argentina to the south and southwest, Brazil to the east and northeast, and Bolivia to the northwest. With an population of 6.5 million inhabitants by 2012, Paraguay is ranked 107 in the Human Development Index by United Nations Development Program (UNDP, 2009). The country has a GDP per capita of USD 4380 (2014), being the second poorest country in South America. Notwithstanding, Paraguayan economy recently has grown at very large rates (about 9\% per year in the period 2010-2012), but with high volatility, mainly as result of increased agricultural exports, especially soybeans and beef. Due to the economic structure of a landlocked country, rivers (Paraguay and Parana) play a key role in the economic life the country. Rivers not only provide access to the Atlantic Ocean to the export product, but also afford as sites for the hydroelectric power plants that have made Paraguay one of the world's largest exporters of hydropower. Under this context, this renewable energy source, compatible with a model of sustainable development, must be the cornerstone of the energy policy in Paraguay. The current energy surplus have to be use for supplying the power demand in the short and medium term with the incorporation of large industries in order to stabilize the economic growth. Moreover, considering the current demand growth, such surplus levels will decrease over the course of time, and it can jeopardize the sustainability of the proposed development policies. Therefore, it is imperative to start the analysis for multicriteria evaluation of the installation of new sources of power generation. In this sense, the proposed work presents the Analytic Hierarchy Process (AHP), to the prioritization of several new strategies of power generation, considering technical, environmental, economic and socio-political criteria, allowing the decision maker, to determine what would be the best alternative power generation for the country.
\end{abstract}

Keywords: power generation, energy demand, multi-criteria evaluation, AHP.

\section{Introduction}

Paraguay is a producer of clean and renewable energy, with high levels of surplus energy. This surplus could be not sufficient to meet demand in the long term under high growing rate levels. Therefore, we proposes an AHP model to develop a hierarchy of potential electricity sources, in order to meet the future demand under the context of a sustainable development.

\section{Literature Review}

Multicriteria approaches have been used in recent years for the classification of various technologies of electricity production (E. W. Stein, 2013), as well as in strategic classification of a comprehensive plan optimal resource (J. Ren and B.K. Sovacool, 2015). In addition, it has been applied as an approach for assessing the energy security of the countries that are dependent on fossil fuels (S. Ahmad and R.M. Tahar, 2014).

\section{Hypotheses/Objectives}


This article proposes the use of AHP, in order to determine the best alternative for power generation, seeking social welfare to the country.

\section{Research Design/Methodology}

We evaluate seven alternatives as potential electricity sources: A1) nuclear power plant, A2) biomass power plant, A3) natural gas power plant (importing gas from Bolivia), A4) natural gas power plant (using own natural resources), A5) wind power plant, A6) solar photovoltaic power plant and, A7) hydroelectric power plant. The four criteria used are: C1) technical, with sub-criteria such as: $S_{11}$ ) typical power; $S_{21}$ ) technological maturity, $S_{31}$ ) fuel availability; $S_{41}$ ) plant factor and; $S_{51}$ ) efficiency; $C 2$ ) economic, considering sub-criteria as: $S_{12}$ ) installation cost; $S_{22}$ ) maintenance cost and; $S_{32}$ ) fuel cost; C3) environmental, with sub-criteria as: $\mathrm{S}_{13}$ ) area used and, $\left.\mathrm{S}_{23}\right) \mathrm{CO}_{2}$ emissions and; C4) sociopolitical, with sub-criteria as: $S_{14}$ ) social acceptance, $S_{24}$ ) Government interest and, $\mathrm{S}_{34}$ ) creation sources of employment. Weights of each alternatives and criteria were determined by a pool of experts in the area of energy in Paraguay, and validate by the calculation of the consistency index.

\section{Data/Model Analysis}

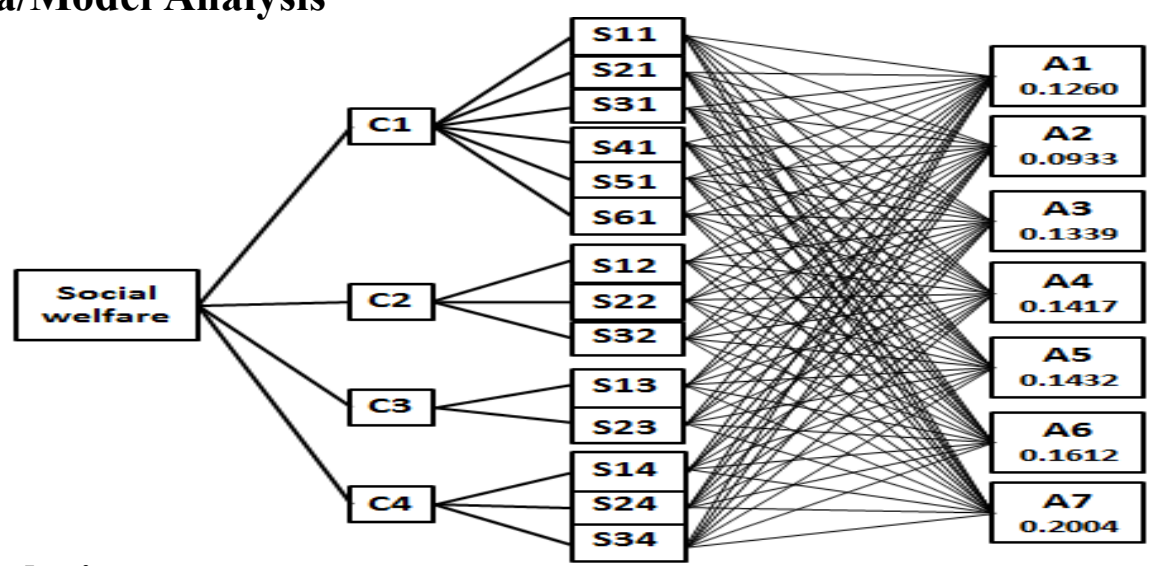

\section{Conclusions}

It has proposed a new approach based on the use of AHP for prioritization of new sources of power generation in Paraguay. We can conclude that the best alternative for the country is the construction of new Hydroelectric Power Plants for the benefit of the society, performing a critical analysis, looking for efficient solutions for the country.

\section{Key References}

E. W. Stein. (2013). A comprehensive multi-criteria model to rank electric energy production technologies. Journal of Renewable and Sustainable Energy Reviews, 22 (2013), 640-654.

J. Ren, B.K. Sovacool. (2015). Prioritizing low-carbon energy sources to enhance China's energy security. Journal of Energy Conversion and Management, 92 (2015), 129-136.

S. Ahmad, R.M. Tahar. (2014). Selection of renewable energy sources for sustainable development of electricity generation system using analytic hierarchy process: A case of Malaysia. Journal of Renewable Energy, 63 (2014), 458-466. 